\title{
Оптический анализ дыхания: индивидуальные острова стабильности
}

\author{
К. Майти ${ }^{1}$, Э. Филл ${ }^{2}$, М. Левтон ${ }^{1}, \underline{\text { А. Аполонский }}^{1,2, *}$ \\ ${ }^{1}$ Max-Planck-Institut fuer Quantenoptik, D-85748 Garching, Germany, \\ ${ }^{2}$ Department für Physik, Ludwig-Maximilians-Universität München, D-85748 Garching, Germany \\ *E-mail: Alexander.Apolonskiy@physik.uni-muenchen.de
}

DOI:10.31868/RFL2018.191

1. Несмотря на большие усилия многочисленных исследовательских групп разных профилей, в настоящее время отсутствуют эффективные дружественные ранние медицинские диагностики. Из-за фундаментальных трудностей массспектрометрии, основного инструмента исследователей, не удается достичь желаемых чувствительности и специфичности при исследовании когорт больных с помощью исследования биологических жидкостей (в жидкой или газовой фазах). Спектроскопия среднего ИК диапазона свободна от принципиальных недостатков, но сталкивается с проблемой высокой концентрации водяных паров в выдыхаемом человеком воздухе. Например, широкие зоны поглощения воды не позволяют исследовать асетон, метан, альдегиды и др. В докладе будет представлена концепция и ее реализация для FTIR спектрометра по подавлению влияния паров воды на три порядка, c результирующей детекционной чувствительностью 50 ppbv.

2. Помимо ограничений детекционной чувствительности, молекулярной селективности и точности измерений, существует еще одна причина неудовлетворительного состояния дел. Она связана с процедурами получения и анализа данных. В качестве демонстрации возможного решения будут представлены результаты двухлетнего исследования дыхания здоровых волонтеров. Во-первых, мы показали, что все процедурные шаги нуждаются в улучшении, а затем, после широкого тестирования, в принятии научным сообществом. Во-вторых, мы показали, что общепринятый слепой анализ данных с помощью principal component analysis (PCA, метод главных компонент) не является надежным. В многопараметрическом же пространстве концентраций выдыхаемых органических молекул каждый волонтер может быть представлен его уникальным набором данных («индивидуальным островом стабильности»). Этот набор остается стабильным по крайней мере 8 месяцев существует большое количество факторов, приводящих к уходу из островного состояния, и болезнь можно рассматривать как один из них. При наличии биопаспорта с зафиксированным положением острова стабильности в многопараметрическом пространстве, изменение состояния человека, отслеживаемое с помощью сдвига его данных относительно положения его острова, может служить универсальным биомаркером, работающим на ранней стадии заболевания. 